ORIGINAL ARTICLE

\title{
Patent value index: Measuring Brazilian green patents based on family size, grant, and backward citations
}

\author{
Adriana Stefani Cativelli 1 , Adilson Luiz Pinto 2 , Maria Luisa Lascurain Sanchez 3
}

How to cite (APA): Cativelli, A.S.; Pinto, A.L.; \& Lascurain Sanchez, M.L. (2020). Patent value index: Measuring Brazilian green patents based on family size, grant, and backward citations. Iberoamerican Journal of Science Measurement and Communication; 1(1).

https://doi.org/10.47909/ijsmc.03

Received date: 6 June 2020

Accepted date: 3 November 2020

Handling editor: Carlos Luis González Valiente

\section{Copyright: () 2020 Cativelli et al.} This is an open access article distributed under the terms of the CC BY-NC 4.0 license which permits copying and redistributing the material in any medium or format, adapting, transforming and building upon the material as long as the license terms are followed.

\section{ABSTRACT}

Objective. The Patent Value Index is created to identify the most valuable patents based on the evidence yielded by different agents in the patenting chain.

Design/Methodology/Approach. The agents and indicators are the following: (a) patent holder (number of countries where the invention is protected); (b) Brazilian IP Office (INPI, the patent-granting agent), and (c) users (number of citations). Brazilian green patents were selected for the application of the index. Data was collected on the Global Patent Index. 478 patents were found, the values of which were calculated by the index. Using the overall score median, the population was divided into two groups: (1) upper-half median (composed of the highest-scoring patents) and (2) lower-half median (lowest-scoring patents).

Results/Discussion. The results identified converging behavior among the values demonstrated by the three agents, as the patents in the first 183 positions evidence that $65.5 \%$ are from foreign countries, $77.6 \%$ belong to companies, $96.2 \%$ have a patent family, $86.9 \%$ have a Patent Cooperation Treaty request, $78.7 \%$ were granted, and $74.9 \%$ are cited by other patents. Regarding the 295 patents of the lower median, $94.6 \%$ are Brazilian, $44.7 \%$ belong to individuals, $22.2 \%$ were granted, $4 \%$ are cited, and $9.6 \%$ have a patent family.

Conclusions. The constructed index can be used for those patentometric studies aimed at investigating qualitative aspects of inventions.

Originality/Value. A value triad, -with data available in databases-, is created to evaluate patents according to different agents in the inventive chain.

1 Universidade Federal de Santa Catarina, Brazil. *(Corresponding author) Email: adrianacativelli@gmail.com. ORCID: 0000-0001-8533-2263

2 Universidade Federal de Santa Catarina, Brazil. ORCID: 0000-0002-4142-2061

3 Universidad Carlos III de Madrid, Spain. ORCID: 0000-0001-9023-4967 
Keywords: Patent value; Patentometrics; Industrial property; Green patents

\section{INTRODUCTION}

Patent research has been increasingly developing, due to the importance that technological information has gained in the age of knowledge. The discovery of new medicines, manufacturing processes, functions that optimize the use of electronic devices, among other inventions, are usually objects protected by the industrial property, specifically, by patents. As a way of measuring the productivity of companies, regions, or countries in terms of knowledge developed, studies are conducted that aimed at raising the number of registered patents. However, the mere counting of patents filed and granted does not indicate the quality of technologies and innovations. It allows assessment of the degree of invention, i.e. what has been newly discovered, but the question that should be asked is: are these inventions being somehow used by society? That is, what counts as innovation within a population of inventions understudy?

For an invention to become an innovation, it must enter the market and generate some kind of return to its holder. In the Theory of Economic Development, Schumpeter (1997) differentiates invention from innovation, stating that innovation is the successful implementation of an invention and that it refers to new combinations of (previously available or unavailable) resources, to produce new goods or open access to new markets. The literature on patent value firmly states that there are many patents with no value and few high-value patents. Stevens and Burley (1997) report that only one to three out of 100 patents may bring significant financial returns, as the chances of any idea becoming an economic success are so low that a high number of ideas is needed.

Patent value researchers try to solve this problem by working with data/indicators available in databases, which can reveal the strategies and market impact of a given invention. The present research intends to create a Patent Value Index (PVI) with indicators that demonstrate the value of a patent, according to the actions of different agents in the patenting chain. The first agent is the patent holder, and the indicator provided is the size of the geographical scope of the protection of the invention, employing the size of the patent family. Holders seek to protect their inventions in the territory they view as a potential market. Thus they need to select the countries they want to protect, where they will spend on registration fees, translation, maintenance, among other items, to ensure that their inventions are not exploited by third parties without their permission and possible profit.

The second agent in this PVI chain is the Brazilian IP Office (INPI), which determines whether an invention meets the inventiveness criteria, and decides whether or not to grant the patent. The last PVI agent is the user, and the indicator they provide is the number of citations. The higher the number of citations a given patent has received, the greater the invention's chances of displaying technological value, as it shows that other inventors are drawing on that invention to develop their own. The PVI seeks to classify inventions so that the most valuable patents according to the above criteria rank higher on the list. It is an experimental index open to future improvement after possible execution flaws are identified.

The chosen research population was the Brazilian green patents registered in the Global Patent Index (GPI) database. The Brazilian Green Patents Program started as a pilot and is currently offered as a service by INPI. This type of invention was chosen because their patents follow a special route of priority examination within patent offices, standing out from the other requests for priority examinations, due to its strategic character, as it aims 
to accelerate the examination of patent applications, the object of which is focused on technologies aimed at sustainable development in areas considered strategic for the Brazilian government. The so-called "green" technologies refer to the following categories: (i) alternative energy sources; (ii) transportation; (iii) energy conservation; (iv) waste management and (v) agriculture (World Intellectual Property Organization (World Intellectual Property Organization, 201?, p. 54). Besides, on the GPI basis, Brazilian patents are the only ones that indicate in their legal event description that they are green. It should be noted that the collection of green patents by their subject classification according to the IPC Green Inventory1 was unsuccessful, as it recovered patents that were not green, as well as left out some that were. The next section will detail the steps of the PVI design.

\section{MATERIALS AND METHODS}

\subsection{Insights for creating the PVI}

Among the papers that tackle patent value indicators, two served as the basis for the design of this index. These papers build value indices that aim to create a filter that may separate valuable patents from others. One of them is van Zeebroeck's (2011) research, which formulates the "composite index" that seeks to collect a series of different measures to provide a consistent score that can be used to weigh or rank patents. The indicators used are backward citations, grants, legal disputes, patent family, and renewal. Zeebroeck states it is a practical approach to classify patents based on each of the different indicators; it is based on the distribution percentiles of each measure and therefore assigns a score to each measure from 1 to 100 . The different scores can then be aggregated into a composite score that can be used to rank or weigh patents by importance. Results point that most indicators are indeed correlated with the monetary value of patents as perceived by their inventors. They also show that the indicators are weakly correlated, displaying evolutions and different industrial standards, and producing different patent classifications.

Grimaldi et al. (2018) create a structure that synthesizes in a single index the results of a multi-criteria approach, based on information derived from quantitative objective data (claims, citations, and market coverage), information related to qualitative determinants (strategic and economic positioning), and information derived from the perceptions and judgments of decision-makers. A weight is assigned to each of the indicators, based on the strength of each dimension. The sum of the weights and the value of each indicator result in the single index value. Indicators values range from 0 to 1 , and the sum of the weight values should be unitary. The research universe is the patents of an Italian global player in the aerospace and defense market. The results of the analysis provided managers with the necessary suggestions on the action items to be carried out: reinforce, license, try to discard or sell some of the patents.

\subsection{Data collection}

The search in the GPI database was undertaken on November 12, 2019, with the following search strategy: EVDE = "green patent". EVDE stands for "event description", by which the basis searches the field regarding the legal records in the patent proceedings in the patent office. After the extraction of the data in comma-separated values (CSV), only patents with the code b27b (which corresponds to the applications granted entry into the Green Patents Program) were kept. Besides, the present research seeks to work only with invention patents. Thus, according to Resolution No. 74/2013 (Instituto Nacional da Propriedade Industrial, 2013), certificate of addition applications begin with number 13, and utility models with numbers 20,21 , and 22 , therefore, patents beginning with those numbers were identified and 
removed from the research population. The oldest patents that had the initials PI (Invention Patent) were kept, and those with the initials MU (Utility Model) were removed from the population. There were then 478 patent families left.

Data on citations were collected in the Derwent Innovation Index (DII) database. A search strategy was developed with all the publication numbers of the 478 green patents in the field "patent number"; the search was conducted on April 03, 2020. The grant data were collected at INPI's database, to ensure the patents' status updating. The search was conducted manually on April 29 and 30, 2020.

\subsection{Theoretical support for the triad value index}

The construction of the PVI is based on three pillars of value perception by different agents. Each component of the triad will account for $1 / 3$ of the total weight to be calculated, as all agents in the chain are of equal importance in demonstrating a given patent's value. Patent holders/applicants are at the beginning of the chain; they express the value the invention will have on the market by selecting a geographical scope to protect it, i.e. value may be measured utilizing patent family size. According to the Patent Statistics Manual (Organisation for Economic Co-operation and Development, 2009), data on patent family size have advantages over others, as they allow the construction of indicators at the beginning of a patent application's life. Its value is associated with its geographical scope of protection, i.e. the number of jurisdictions where a patent has been applied for (Organisation for Economic Co-operation and Development, 2009).

This pillar of the VPI is directly linked to private value because it enables an estimate of the expenses the patent owner had when seeking the protection of the invention in the global market. Martínez (2010) corroborates by pointing that the overseas patent application is associated with higher costs for the applicant, in terms of Patent Office fees, lawyer accounts, and translation costs. Applicants who choose to follow this path may be seen as demonstrating that the time, effort, and cost associated with it are worth it, that is, they would only be willing to do so if the expected commercial value of the invention is high enough (Martínez, 2010). The count of the number of members of a patent family may vary depending on the research objective to be achieved. Based on an in-depth study on patent families, Martínez (2010) explains that there is no legal definition of family; each database producer defines it according to their convenience.

The present study will count the number of countries where the invention seeks protection to determine patent family size. The intention was to measure the geographical scope of protection of the invention, which, for Lee and Shon (2017), may reflect its market potential; protection in a large number of countries may imply potential commercialization and profitability. It is important to bear in mind that the GPI database does not indicate which patents of the family have been granted; therefore, patent families are counted by applications.

Also, this component will adopt a distinct weight for patent families that have triadic patents and Patent Cooperation Treaty (PCT) applications. The literature justifies describing a higher weight to patent families with these features by stating that triadic patents, -those that apply for protection in the world's major markets, Europe, Japan, and the United States-, can be used as an indicator of patent intensity, due to the importance of the three offices involved; they may also be used to collect the highest valuing inventions to draw comparisons between countries (Organization for Economic Co-operation and Development, 2009). Martínez (2010) highlights this idea by reporting that there are different indicators of internationalization and 
geography of inventions, based on data from patent families that seek to capture different effects, and one of the most used are triadic families, which requires that family members be deposited in the three main patent offices: United States, Japan, and Europe. Besides, many studies have shown the existence of a high correlation between triadic families and patent value, which makes triadic families a common indicator used by researchers and statisticians to analyze the most valuable patents of a country (Martínez, 2010).

In its turn, the PCT application does not imply that the patent has been protected in all countries that are part of the cooperation treaty, rather than the patent applicant will have more time to make strategic decisions. The PCT procedure offers the possibility of seeking patent rights in many countries, by registering a single international application in a single patent office. It is subsequently necessary to enter the national stage in the desired countries, where they need to be validated/granted (Organization for Economic Co-operation and Development, 2009). Therefore, it is possible to significantly postpone national or regional procedures (until the end of the thirtieth month from the priority date) by a unified filing procedure, which gives applicants more time to meet national requirements, and assess their chances of being granted patents and exploring the invention - by estimating competition, finding licensed parties, etc. (Organization for Economic Co-operation and Development, 2009).

Given the above, the PCT application was seen as yielding strategic advantages to the applicants, which patent scholars regard as more valuable. Martínez (2010) points that transnational families, -patent families that have applied for PCT and the European Patent Office (EPO)-, work as a quality filter, as grants are applied for by supranational procedures only for patents with high projected commercial value. The Organization for Economic Co-operation and Development (2009) views the PCT as the most popular route among inventors targeting world markets, i.e. targeting world markets is a sign that their inventions have great market potential.

The next indicator is related to patent offices - responsible for ascertaining whether the invention complies with all patentability requirements -, as they express value by granting patents. The literature highlights that it is one of the first indicators of the quality of an invention (Organization for Economic Co-operation and Development, 2009). Liu et al. (2014) explain that, if the patent meets the statutory requirements for a grant, it means that it has "technological value" or "social value". Granting a patent indicates that an invention is officially recognized as fulfilling the criteria of patentability: novelty, inventive step (non-obviousness), and industrial applicability. Such patents have higher technological and economic value than unsuccessful patent applications (Organization for Economic Co-operation and Development, 2009).

The last value indicator is expressed by users in general; these agents express value by the number of citations a given patent has received, i.e. the patent is acknowledged as a technological basis for the development of other inventions. According to the Organization for Economic Co-operation and Development (2009), future citations can be used to assess the technological impact of inventions, for example, their cross-technology and/or geographical impact. Their technological impact, in turn, may indicate the economic importance of patents on the market. Sapsalis et al. (2006) reinforce this theory when they state that technological value can be revealed by the number of backward citations, and add: when monetary value is not available, the literature relies on the number of citations as a good substitute for patent value. 


\subsection{Method}

The PVI seeks to balance the scores' inventions reach in each indicator concerning the larger set. The indicators that present continuous values, such as family size and citations, will be calculated as shown in figure 1.

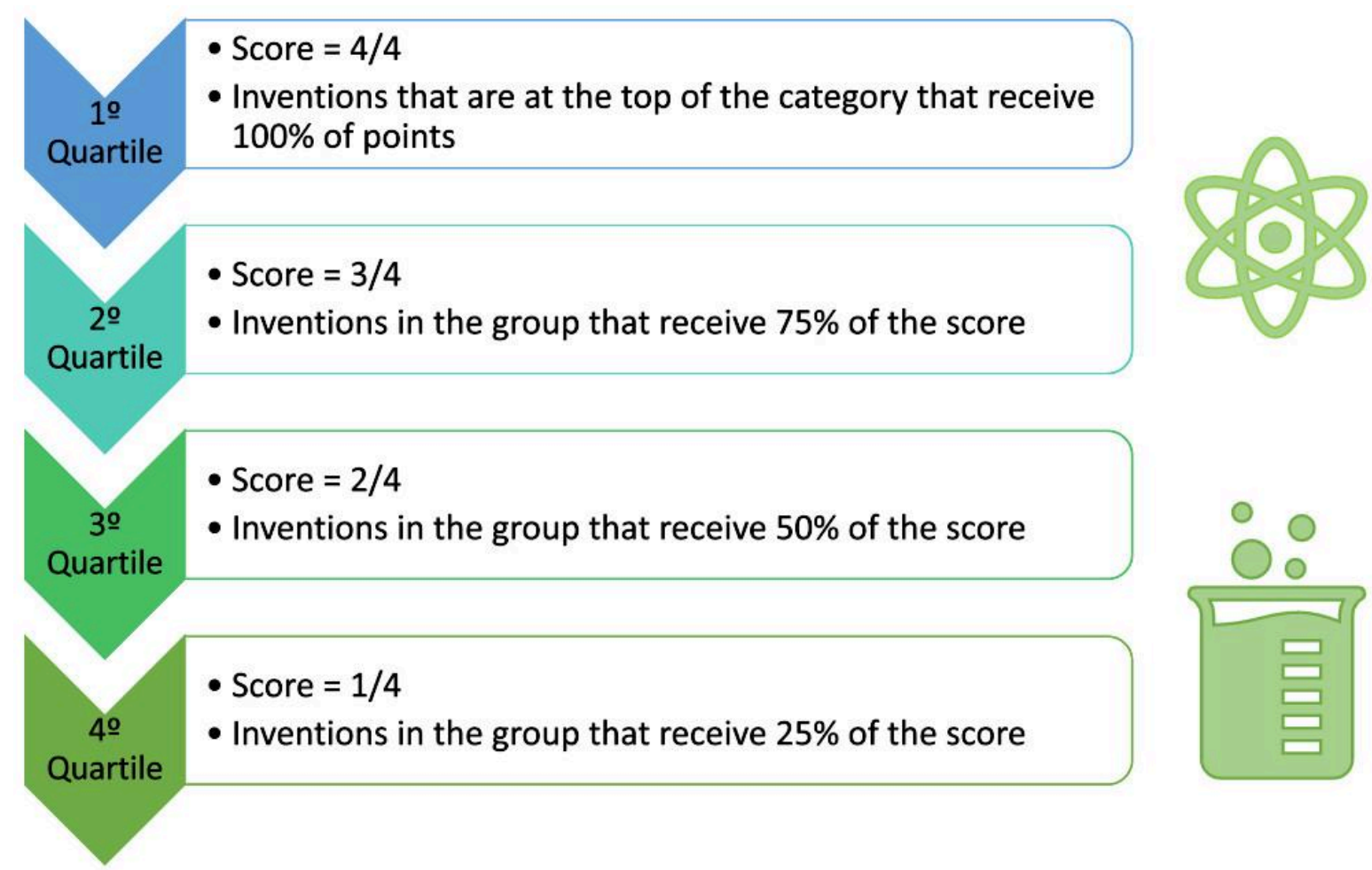

Figure 1. Quartiles of the distribution of weights of continuous indicators (Source: The authors, 2020).

As may be observed in figure 1 , each quartile represents $1 / 4$ of the data population. The separation of the data into groups aims to partially correct the discrepancy in values, to assign fairer grades, as few patents received many citations and many patents with few or no citations. For the family indicator, the logic is the same; however, $10 \%$ of the general grade will be assigned to patent intensity features - namely, PCT applications and triadic families -, as stated above. Regarding grant, values are 0 (not granted) and 1 (granted). Each variable will receive $1 / 3$ of the general grade, so the final equation is:

Total value $=$ family $^{*} 0.9+$ triadic-value ${ }^{*} 0.05+$ PCT-value ${ }^{*} 0.05+$ grant $^{*} 1+$ citation $^{*} 1$

\subsection{Application of the method in the Brazilian green patent population}

As previously stated, the three indicators will receive equal weights in the equation, i.e. family size, grant, and citations will each score from 0 to 1 . The final formula is the sum of the three values. However, each will be calculated in different ways, to accommodate their specificities. A discrepancy was noted between the most cited patents and the others. The data were thus divided into four groups, with fixed weights being assigned each, to better balance the measures. See figure 2 below. 


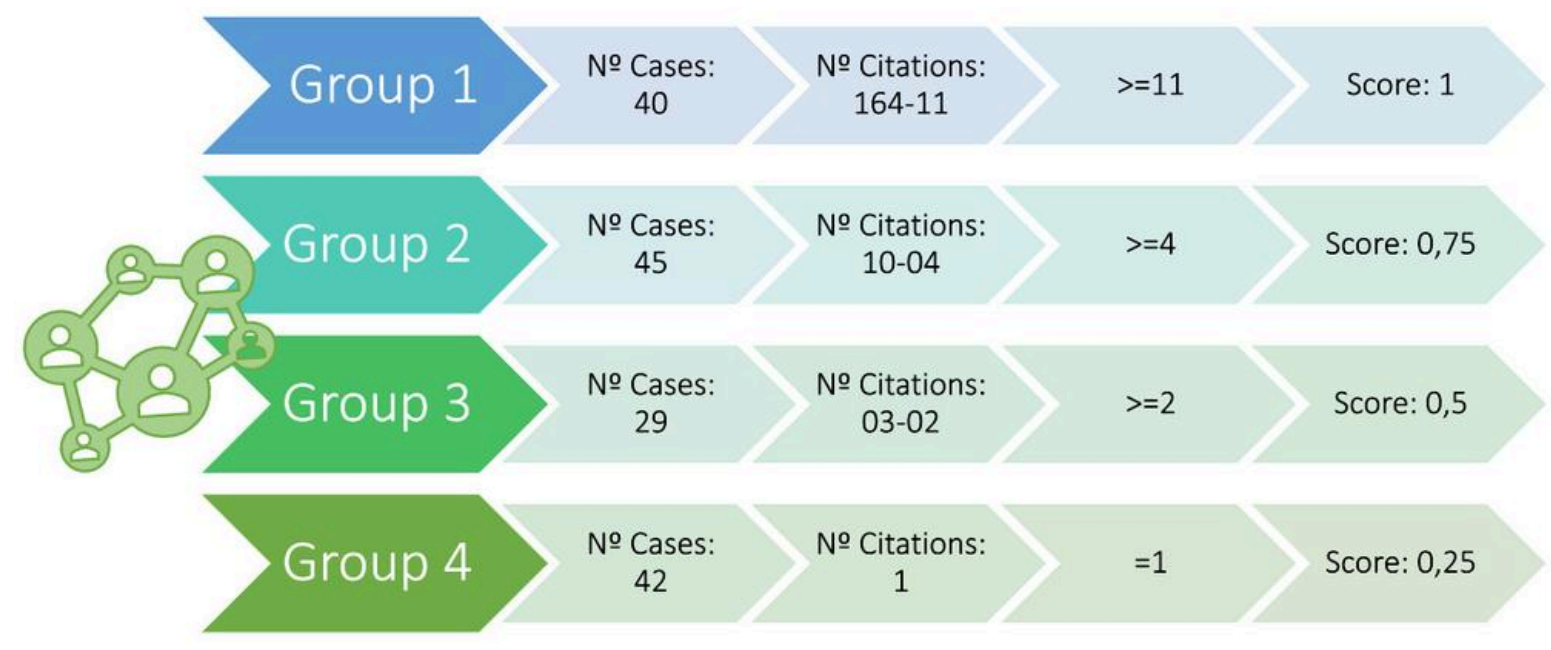

Figure 2. Group division and weight assignment for the citation indicator (Source: The authors, 2020).

The elected population contains 156 patents that were cited at least once. Dividing that number by four, each group should have 39 patents, but that proved impossible. In the case of group 1, for example, both cases 39 and 40 contain 11 citations each and therefore had to be grouped. It was thus necessary to divide cases into groups unevenly, so that some have more patents than others - as is the case of group 3, the smallest, with only 29 cases. The weights of the patent groups were also divided by four, with group 1 receiving the highest grade, group 2 receiving 3/4 of 1 , Group 3 receiving 2/4 of 1 , and Group 4 receiving 1/4. The third column shows the mechanisms used to calculate the values in the spreadsheet software.

As for data on the family, the same division of citations was also adopted, however, since the family presented distinct characteristics, as explained in the index theory, $10 \%$ of the weight attributed to families was reserved for patents that applied for PCT and belong to a triadic family. According to the literature, patents with these characteristics have greater value, and thus it was decided that they should be given heavier weights. To illustrate this situation, Grimaldi et al. (2018) perform the following calculation for the family indicator. Market coverage values range from 0 to 0.7 , in three situations: 0.1 if the patent is granted in the United States, 0.2 if the patent is granted in more than two European countries, and up to 0.4 if the patent is granted in more than six countries outside Europe. In addition, the patents are valued zero or 0.3, depending on two different situations: PCT application and triadic participation. Figure 3 shows how the division was for this indicator was done. 


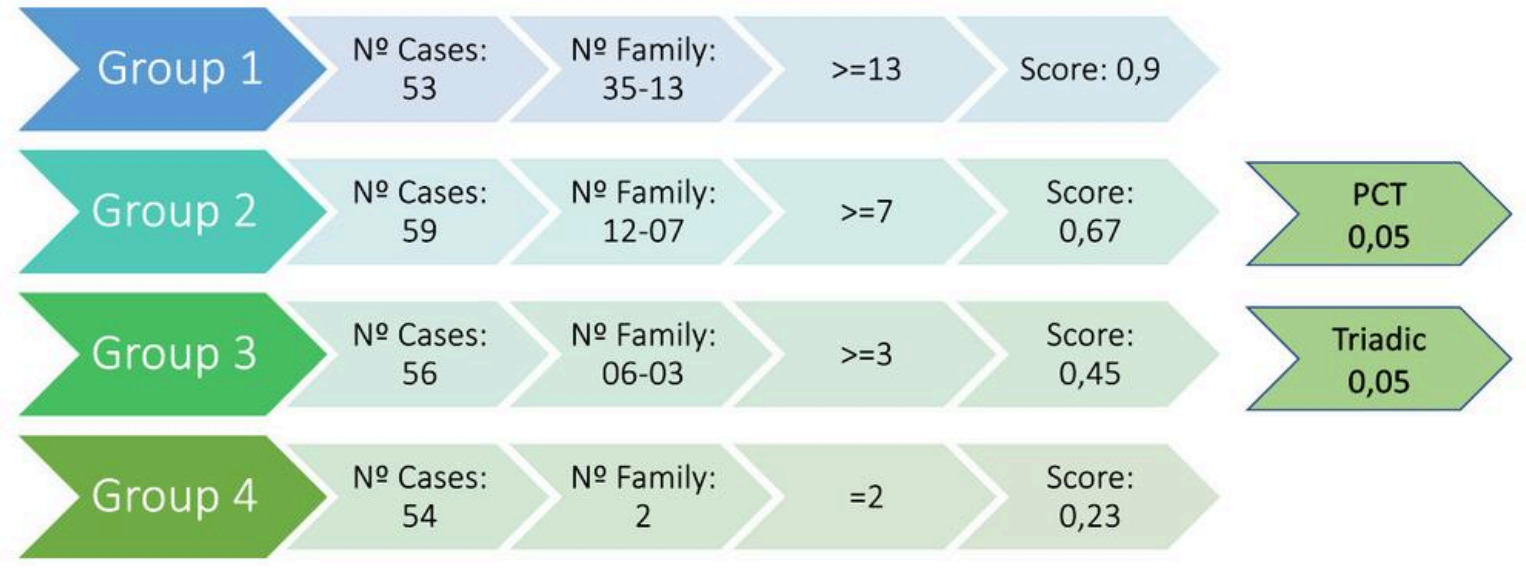

Figure 3. Group division and weight assignment for the family indicator (Source: The authors, 2020).

The maximum grade that a patent can be assigned by the number of family components is 0.9. To reach the maximum score, it must also have applied for PCT and belong to a triadic family. The grant indicator is calculated in the same manner as PCT application and triadic participation: granted patents score 1 , and non-granted patents score 0 . The final equation will be the sum of the 5 values, with 3 being the maximum score a patent can receive. The calculation is done using Libre Office Calc, the spreadsheet component of the LibreOffice free software package. Figure 4 shows the step-by-step process to calculate the PVI.

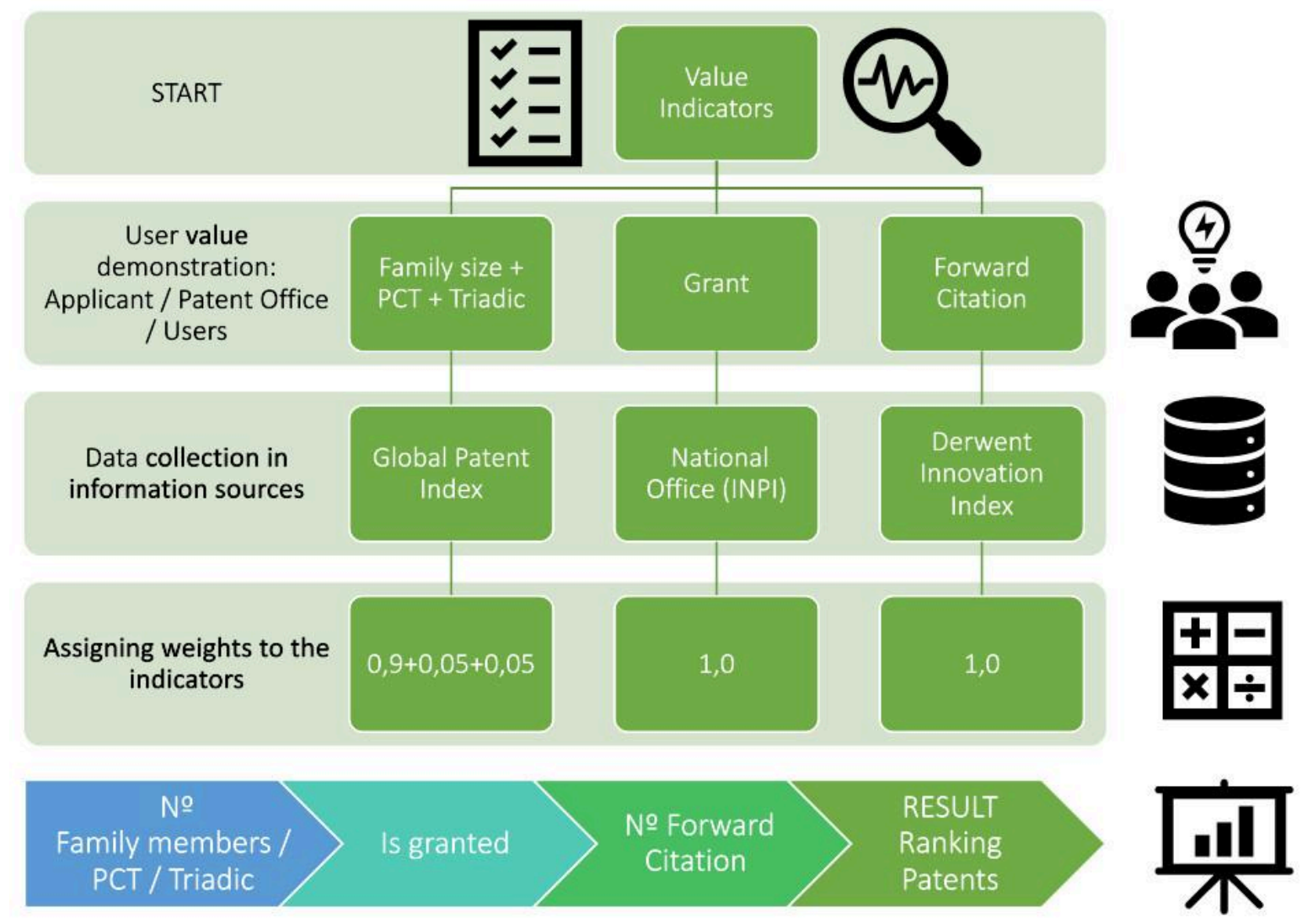

Figure 4. PVI construction diagram (Source: The authors, 2020). 
The triad of value theory and its index does not intend to pinpoint precisely which patents have or do not have economic value in the market. This can only be obtained together with the patent owners or employees of the offices that are involved in the patenting process. What the index seeks to assess is a way to calculate the indicators that present patent value as demonstrated by each of the agents in the chain, while trying to separate innovations from inventions.

\subsection{Limitations of collected data}

The value index created in this research was developed according to the limitations that databases impose concerning data collection. Data on grants only took INPI into account, so the members of the patent families collected are related to grant requests. As for data on citations, the occurrence of self-citation was not ascertained, as this task would have to be performed manually, patent by patent. We also used all the green patents that appeared in the GPI, without making the 5-year cut present in the literature when counting patent citations, as this period is taken into account until the patent receives its first citations (Fischer \& Leidinger, 2014).

\section{RESULTS}

The patent value indicators collected from the 478 records show that most green patents are scarce in such indicators. The grant indicator was the only one that seemed to show in a small majority about non-grant, with 250 patents granted and 228 not granted. The numbers may be seen in figure 5 .

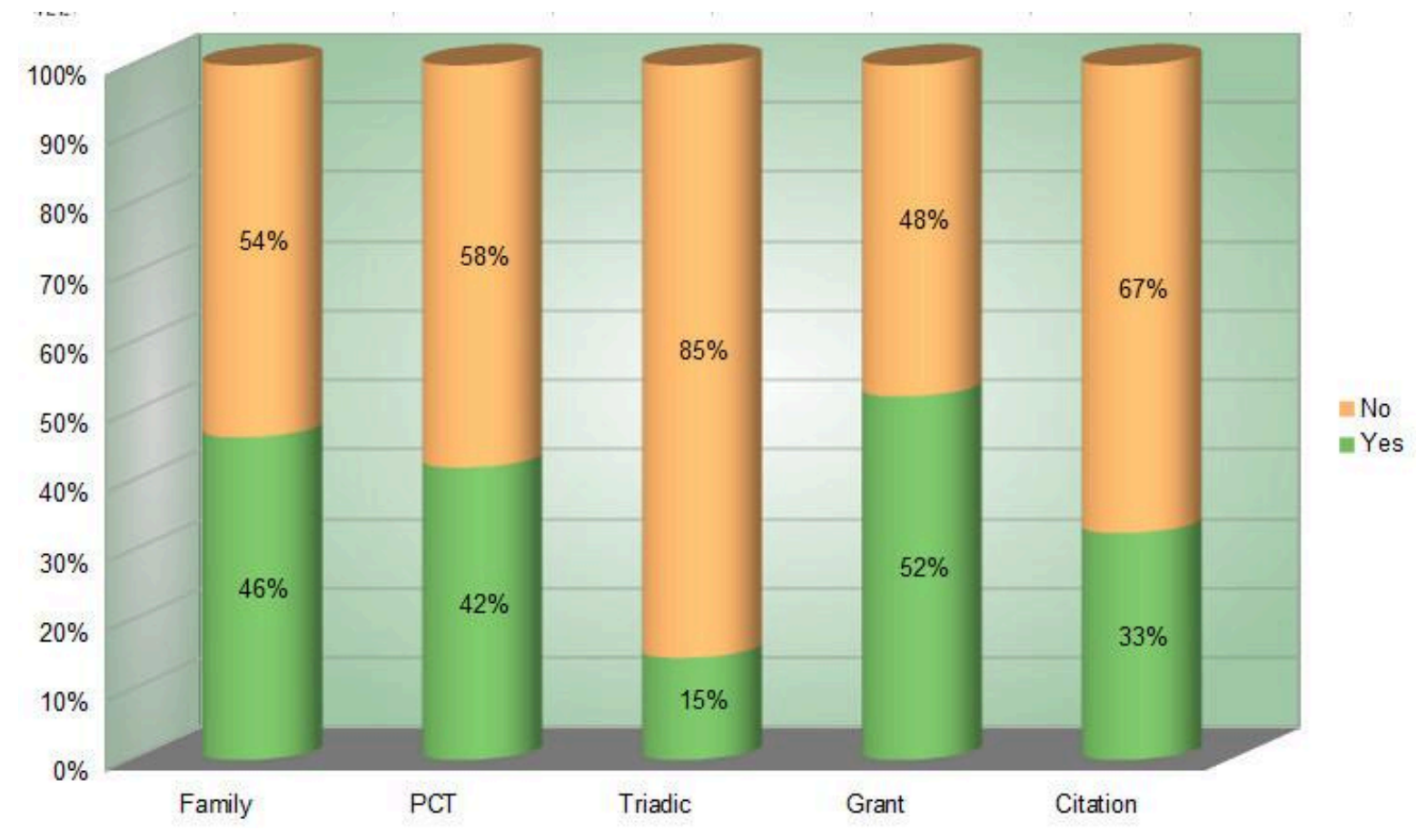

Figure 5. Brazilian green patents value indicators (Source: The authors, 2020).

Another indicator displaying significant numbers is patent family, with 222 patents with families, and 256 without. The PCT application indicator also shows a considerable volume of favorable registrations: 201 patents have entered PCT applications, and 277 have not. The other two indicators, citation, and triadic family were the features that appeared the least in 
the population of Brazilian green patents. 156 were cited, and 322 not cited; there were 70 triadic patents and 408 non-triadic ones. As for the index data, the mean, mode, and median of each indicator were analyzed, as well as the general grade received. The numbers are presented in figure 6 .

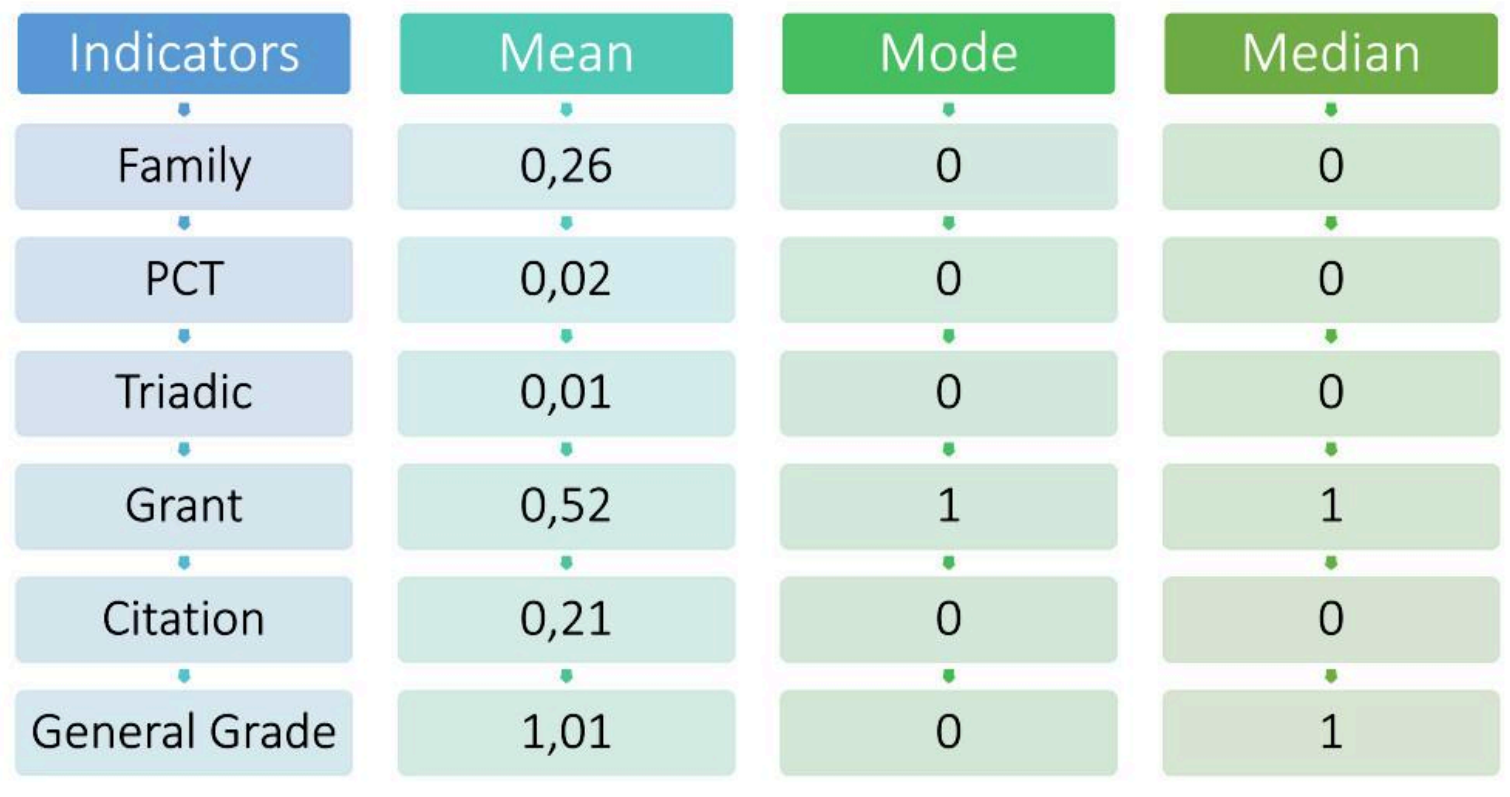

Figure 6. Descriptive statistics of patent value indicators (Source: The authors, 2020).

The grant indicator may be seen to present the highest grades, also presenting a mode and a median. The other indicators could not reach any mode or median, as the records in these categories were few about the total set. Eight patents received the maximum grade (3) in the PVI (see the full list in Appendix A). We present below the features of the highest-ranking patents. All patents in Table 1 were granted in Brazil, belong to a triadic family, and have applied for PCT.

Table 1. Features of the highest-ranking patents in the PVI (Source: The authors, 2020).

\begin{tabular}{|c|c|c|c|c|c|c|}
\hline Patent $N^{\circ}$ & $\begin{array}{l}\text { Deposit } \\
\text { year }\end{array}$ & $\begin{array}{l}\text { Institution } \\
\text { name }\end{array}$ & $\begin{array}{l}\text { Holder's } \\
\text { country }\end{array}$ & $\begin{array}{l}\text { \# of } \\
\text { countries } \\
\text { requesting } \\
\text { patent } \\
\text { protection }\end{array}$ & $\begin{array}{c}\# \\
\text { cites }\end{array}$ & Field of knowledge* \\
\hline BR PI0818458 & 2008 & $\begin{array}{l}\text { Lanzatech } \\
\text { New } \\
\text { Zeland } \\
\text { Limited }\end{array}$ & New Zeland & 15 & 44 & $\begin{array}{l}\text { Y02A 50/2341 physical or chemical } \\
\text { processes, e.g. absorption, adsorption, } \\
\text { or filtration, characterized by the type of } \\
\text { pollutant }>\text { carbon monoxide }\end{array}$ \\
\hline BR PI0921036 & 2009 & Xyleco & $\begin{array}{l}\text { United } \\
\text { States }\end{array}$ & $\begin{array}{l}\text { Table } \\
\text { content }\end{array}$ & 16 & Y02E 50/10 biofuels \\
\hline BR PI1008565 & 2010 & Xyleco & $\begin{array}{l}\text { United } \\
\text { States }\end{array}$ & $\begin{array}{l}\text { Table } \\
\text { content }\end{array}$ & 24 & Y02E 50/13 Biodiesel \\
\hline $\begin{array}{l}\text { BR PI } \\
1013007\end{array}$ & 2010 & Xyleco & $\begin{array}{l}\text { United } \\
\text { States }\end{array}$ & $\begin{array}{l}\text { Table } \\
\text { content }\end{array}$ & 26 & Y02E 50/16 Cellulosic bioethanol \\
\hline
\end{tabular}




\begin{tabular}{|c|c|c|c|c|c|c|}
\hline Patent $\mathbf{N}^{\circ}$ & $\begin{array}{l}\text { Deposit } \\
\text { year }\end{array}$ & $\begin{array}{l}\text { Institution } \\
\text { name }\end{array}$ & $\begin{array}{l}\text { Holder's } \\
\text { country }\end{array}$ & $\begin{array}{l}\text { \# of } \\
\text { countries } \\
\text { requesting } \\
\text { patent } \\
\text { protection }\end{array}$ & $\begin{array}{l}\# \\
\text { cites }\end{array}$ & Field of knowledge* \\
\hline $\begin{array}{l}\text { BR } \\
2012001642\end{array}$ & 2010 & $\begin{array}{l}\text { Technische } \\
\text { Universiteit } \\
\text { Delft }\end{array}$ & Netherlands & $\begin{array}{l}\text { Table } \\
\text { content }\end{array}$ & 15 & Y02E 50/16 cellulosic bioethanol \\
\hline $\begin{array}{l}\text { BR } \\
112014014000\end{array}$ & 2012 & $\begin{array}{l}\text { Monsanto } \\
\text { Technology } \\
\text { LLC }\end{array}$ & $\begin{array}{l}\text { United } \\
\text { States }\end{array}$ & $\begin{array}{l}\text { Table } \\
\text { content }\end{array}$ & 15 & - \\
\hline $\begin{array}{l}\text { BR } \\
112014028704\end{array}$ & 2013 & $\begin{array}{l}\text { Isis } \\
\text { Innovation } \\
\text { Limited }\end{array}$ & $\begin{array}{l}\text { United } \\
\text { Kingdom }\end{array}$ & $\begin{array}{l}\text { Table } \\
\text { content }\end{array}$ & 14 & $\begin{array}{l}\text { Y02E10 / } 549 \text { Materials Technologies > } \\
\text { organic photovoltaic cells }\end{array}$ \\
\hline $\begin{array}{l}\text { BR } \\
112015019381\end{array}$ & 2014 & Xyleco & $\begin{array}{l}\text { United } \\
\text { States }\end{array}$ & $\begin{array}{l}\text { Table } \\
\text { content }\end{array}$ & 19 & Y02E 50/16 cellulosic bioethanol \\
\hline
\end{tabular}

*The Y02 symbol classification was inserted in the Cooperative Patent Classification (CPC), which identifies technical attributes of technologies regarded as clean energy technologies - a specific sub-sector of climate change mitigation technologies (Bastos, 2018).

The highest-ranking patents belong to foreign countries; seven of them are companies, and only one comes from a higher education institution. Half of these patents belong to Xyleco - a private scientific research and manufacturing company, which develops processes to convert biomass into useful products (Xyleco, 2020). All its technologies are deposited under Y02E 50 , which corresponds to technologies to produce fuel of non-fossil origin. Another result to be highlighted is that neither the patent with the highest number of citations nor the one with the highest number of countries in its family were among the first patents in the ranking. This is because the most cited patent has not yet been granted in Brazil; it also has a considerable number of countries in its family (17), a PCT application, and is triadic. It is positioned in the set of patents that ranked 17 th, with a grade 2 . In this same set, there appear the first patents of the PVI that, although they have not been granted, were assigned maximum grades in citations and patent family number.

The patent with the largest number of countries in its family - i.e. the largest geographical scope of protection - ranked 9th, with a score of 2.50. This invention, filed in 2012 and published in 2015, obtained a low number of citations (only 2), which led it to be graded 0.50 in this category. Another analysis sought to take into account two other factors that separated the patents into four groups: citation in due time and score achieved. In the first case, patents with five years or less (2015-2018) were separated from the others. In the second case, the median score (1, with the group that reached this score located in the lower half) was used to separate the population into the upper and lower median groups. The results may be seen in table 2.

Table 2. Descriptive statistics of the different groups separated by a period of time, and upper-half and lower-half medians of the patent value indicators (Source: The authors, 2020). 


\begin{tabular}{|c|c|c|c|c|c|c|c|}
\hline Indicators & Mean & Mode & Median & Indicators & Mean & Mode & Median \\
\hline \multicolumn{4}{|c|}{ 2004-2014 (319 patents) } & \multicolumn{4}{|c|}{ 2015-2018 (159 patents) } \\
\hline Family & 0.3 & 0 & 0.22 & Family & 0.18 & 0 & 0 \\
\hline РCT & 0.02 & 0 & 0 & PCT & 0.01 & 0 & 0 \\
\hline Triadic & 0.01 & 0 & 0 & Triadic & 0 & 0 & 0 \\
\hline Grant & 0.54 & 1 & 1 & Grant & 0.48 & 0 & 0 \\
\hline Citation & 0.28 & 0 & 0 & Citation & 0.05 & 0 & 0 \\
\hline General grade & 1.16 & 0 & 1 & General grade & 0.72 & 0 & 1 \\
\hline \multicolumn{4}{|c|}{ Median - upper half (183 patents) } & \multicolumn{4}{|c|}{ Median - lower half (295 patents) } \\
\hline Family & 0.59 & 0.67 & 0.67 & Family & 0.06 & 0 & 0 \\
\hline PCT & 0.04 & 0.05 & 0.05 & PCT & 0.01 & 0 & 0 \\
\hline Triadic & 0.02 & 0 & 0 & Triadic & 0 & 0 & 0 \\
\hline Grant & 0.79 & 1 & 1 & Grant & 0.36 & 0 & 0 \\
\hline Citation & 0.5 & 0 & 0.5 & Citation & 0.02 & 0 & 0 \\
\hline General grade & 1.94 & 1.28 & 1.77 & General grade & 0.44 & 0 & 0.28 \\
\hline
\end{tabular}

The groups on the left reached higher scores than the other two groups on the right. This is because, in the first case, the 2004-2014 group has higher chances of being cited, as their patents were issued long ago. Conversely, some patents in the 2015-2018 group are still pending - despite INPI's claims that the examination time takes two years. The figures for the upper-half median group - the highest-ranking patents according to the PVI classification allow for inferences in almost all fields. The highlights of these results are the following:

a. The grant indicator was the main responsible for ranking in the top positions.

b. The number of distinct components of the patent family was the second determinant for the assignment of the final grade. A mean of 0.59 was reached, i.e. an average of 7 to 12 countries per family.

c. The citation was an indicator found in a small portion of the Brazilian green patents population, and this was reflected even in the upper group, which scored 0.5 , that is, an average of only two citations per patent.

d. The PCT application is present in a large portion of the group; the average was 0.4 , and the total weight value of this indicator is 0.5 for the family of patents that presented it.

e. The average grade per patent of the group that is considered to contain the most valuable inventions (and possibly innovations) is 1.94 .

Figure 7 displays the differences in the features of the patents seen as more valuable compared to the others. 


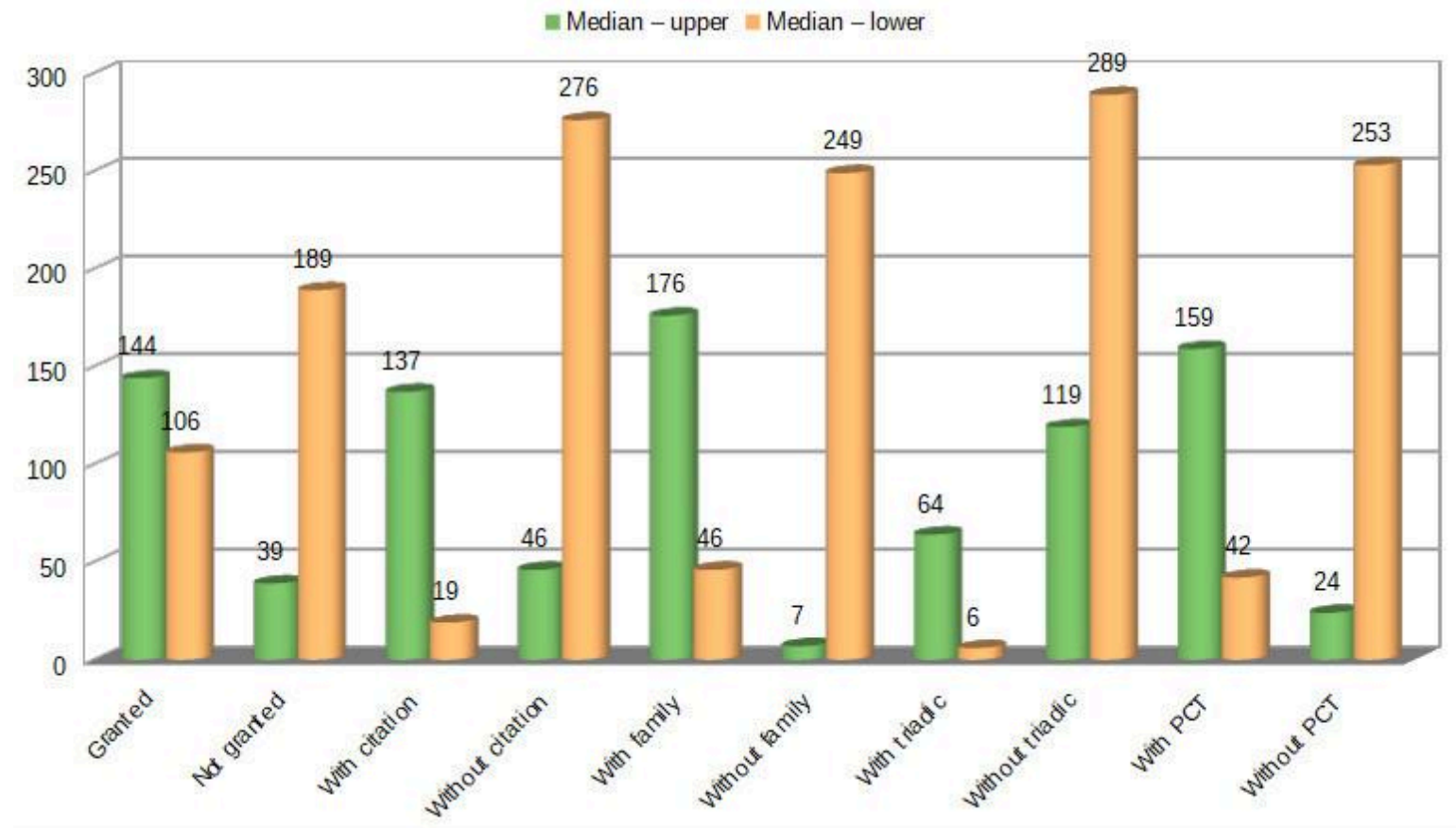

Figure 7. Comparison between the patent value indicators of the upper and lower medians (Source: The authors, 2020).

Figure 7 shows the determining features (represented by the green columns) of the upper median, compared to the orange columns, which represent the figures of the lower-half median population. Only 7 out of the 183 patents in the upper median have no family, only 24 have not applied for the PCT, and 39 have not yet been granted. Another aspect that draws attention, this time about the lower median of the PVI, is that only 19 out of the 295 patents registered the occurrence of citations, and 249 of them have no family. Therefore, there seems to be a pattern, in that inventions that have patent families are more likely to be cited. In addition, it was also considered essential to investigate which countries the patents come from, as well as the type of institution to which they belong. These results are presented in figure 8.

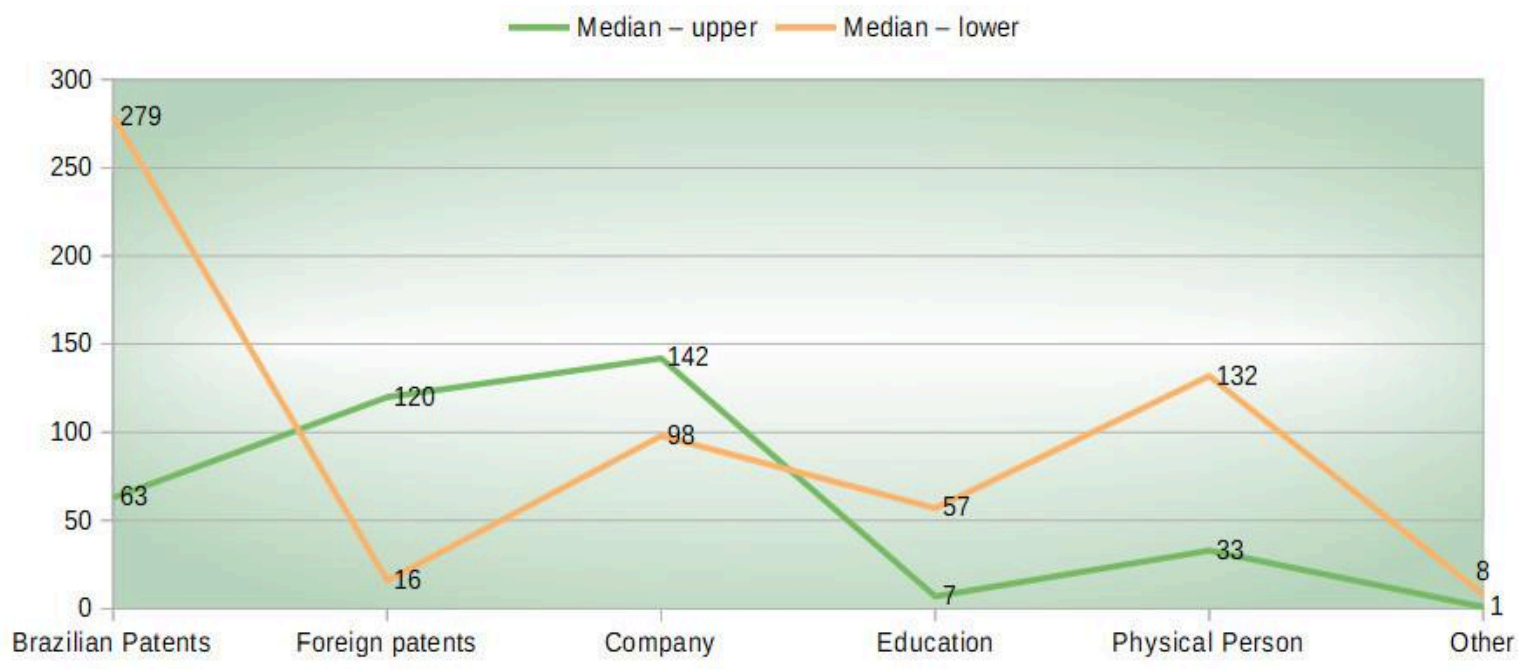

Figure 8. Comparison between upper and lower median patent features (Source: The authors, 2020). 
It is important to remember that the upper median group has 183 patents, and the lower median group has 295. The green line in figure 9 shows the patents that are best classified according to the PVI: $65.6 \%$ of the patent holders are foreign, and $34.4 \%$ are Brazilian. As for the type of institution to which these patents belong, the vast majority originates in companies $(77.6 \%)$, followed by individuals $(18 \%)$, higher education institutions $(3.8 \%)$, and other types of institutions $(0.5 \%)$. The orange line represents patents that reached $1 /$ 3 of the general grade or less; $94.6 \%$ of them originate in Brazil and only $5.4 \%$ in foreign countries. Individuals originate $44.7 \%$ of these patents, followed by companies $(33.2 \%)$, higher education institutions (19.3\%), and other types of institutions $(2.7 \%)$.

The profiles of the two groups of patents are distinct; patents of the best-evaluated group according to the PVI are predominantly from foreign companies. As for the second less prestigious group, they are Brazilian patents belonging mostly to individuals. According to Sapsalis et al. (2006), corporations protect their inventions more widely than universities. The authors explain that this can occur due to a better understanding of and access to end markets, as well as greater availability of financial resources for patenting activities. They also add that a patent applied by a company is protected in 31 countries on average, while a patent applied by a university is protected in 7 countries or regions (Sapsalis et al., 2006). This factor may have contributed to companies' patents scoring higher than patents belonging to other types of holders - as having a family was one of the determining indicators in obtaining PVI scores, as shown in figure 8.

Consequently, the following pattern was identified: $65.5 \%$ of the patents in the first 183 positions of the PVI come from foreign countries, $77.6 \%$ belong to companies, $96.2 \%$ belong to a patent family, $86.9 \%$ applied for PCT, $78.7 \%$ were granted, and $74.9 \%$ are cited by other patents. As for the 295 patents of the lower median, $94.6 \%$ are Brazilian, $44.7 \%$ belong to individuals, $22.2 \%$ were granted, $4 \%$ are cited, and $9.6 \%$ belong to a patent family.

\section{DISCUSSION AND CONCLUDING REMARKS}

One of the purposes of the literature on patent value is to identify valuable patents. Each researcher embarks on this journey with the resources they have at hand. The patent value may have different dimensions, such as:

a. Economic value - also referred to as market value, which can be defined as the difference between future profits and likely profits (Ni et al., 2015).

b. Private value - the value of the use of the invention as an asset, or the value of the invention plus the value of the right to exclude others from the use of the invention (Giummo, 2010).

c. Social value - designates the contribution of the invention to social well-being, including future technological developments and the value of current commercial applications (Baron \& Delcamp, 2012).

d. Technological value - the long-term importance of a patent as a basis for subsequent technological inventions (Yang et al., 2015).

The indicators used in the present research show some of these dimensions. As stated earlier, the patent family indicator - alongside the triadic family and the PCT application - is directly linked to private value, as it represents the investment that the patent holder is making 
on the world market. The grant indicator also seems to be more linked to private value, as it means excluding third parties from exploiting the invention. Liu et al. (2014) state that a patent is endowed with technological or social value if it meets the statutory requirements for a grant.

As for the citation indicator, the literature is unanimous in using it as expressing value in all dimensions. According to Fischer and Leidinger (2014), the higher the technological quality of the patent, the more inventions should be based on the underlying invention of the focal patent, thereby increasing the value of their right of exclusion. That is, here we have technological and private values. Sapsalis et al. (2006) explain that, when monetary value is not available, the literature relies on the number of citations as a good substitute. Therefore, each indicator may be seen to represent a value dimension, and depending on users who elaborate a PVI, they can add elements or use different weights, as they deem necessary.

After being tested, the PVI developed in this study showed that the grant indicator is not suitable to be used with the same weight as the others, unless one wishes to obtain the private value of exclusion from third parties, as this data was verified only at INPI, and not in the other offices for which the patent families also applied. For example, patent BR PI0409750 was filed in 2004, has 73 citations, and is protected in 10 countries, but it was not granted, and its holder continues to pay the annuities, probably to reverse the situation; evidence points that the patent is likely to have been granted in other countries.

The constructed PVI is believed to be is an experiment towards an improved index that will soon emerge from the continuation of this research. In addition to the shortcomings found about grants, it is believed that citations should also be calculated more appropriately, taking the age of each patent into account. Notwithstanding, the targeted goal - the creation of an instrument that would allow assessment of value expression by different agents -, was achieved. Therefore, the current Patent Value Index contemplates indicators that express an invention's value. These are not mere data of characteristics of the document; behind them, it is possible to glimpse the strategy of the holders, as well as the invention's acknowledgment by IP offices and users who draw upon the invention as a technological basis to elaborate their patents. Certainly, the balance of the constructed triad guarantees higher scores, as the demonstration of value by only one or two agents of the chain does not guarantee the first positions, demonstrating a lack of balance, and a consequent shortcoming.

As to accurately defining whether the top-ranking patents in the PVI are in fact innovations and not inventions, patent holders should be consulted, which requires more research time to develop questionnaires or conduct interviews, as well as availability on the part of these applicants. However, this was not the purpose of this investigation. Another discovery which may strengthen PVI's credibility was the fact that the green patents filed in Brazil and considered more valuable come mostly from foreign companies. If a given institution has more resources to invest in its invention, it will certainly do so by protecting it in a larger market; the value of inventions is further endorsed by the fact that the most cited patents belong to the group of inventions with a larger geographical scope.

It is concluded that the constructed index can be used for patentometric studies aimed at investigating qualitative aspects of inventions. When there is a large volume of documents, and it is necessary to identify those that have greater relevance, whether, for an institution, area of knowledge, or country, patent value indicators can be of help. 
NOTES

[1] https://www.wipo.int/classifications/ipc/en/green_inventory/

\section{CONFLICTS OF INTEREST}

The authors declare that there is no conflict of interest.

CONTRIBUTION STATEMENT

Conceptualization, Data curation, Formal analysis, Investigation, Methodology, Supervision, Visualization, Project administration, Writing - original draft, Writing review \& editing: Adriana Stefani Cativelli.

Conceptualization, Data curation, Methodology, Validation, Writing - review \& editing: Maria Luisa Lascurain Sanchez, and Adilson Luiz Pinto.

\section{STATEMENT OF DATA CONSENT}

The classification of Brazilian green patents in the patent value index generated during the development of this study has been deposited in Figshare and it can be accessed at https://doi.org/10.6084/m9.figshare.13221137.

\section{FUNDING}

This work was carried out with the support of the Coordination of Improvement of Higher-Level Personnel - Brazil (CAPES) - funding Code 001.

\section{ACKNOWLEDGMENTS}

We thank Fabiano Seixas Fernandes for the translation service provided.

\section{REFERENCES}

Bastos, R. Q. (2018) Análise de incentivos às tecnologias verdes no sistema de patentes utilizando indicadores de valor. (Dissertação de Mestrado Profissional em Tecnologia de Processos Químicos e Bioquímicos, Universidade Federal do Rio de Janeiro, Rio de Janeiro, Brasil). Retrieved from http://186.202.79.107/download/ incentivos-as-tecnologias-verdes-no-sistema-de-patentes-utilizando-indicadores-de-valor.pdf

Baron, J., \& Delcamp, H. (2012). The private and social value of patents in discrete and cumulative innovation. Scientometrics, 90, 581-606. https://doi.org/10.1007/ s11192-011-0532-5

Fischer, T., \& Leidinger, J. (2014). Testing patent value indicators on directly observed patent value - An empirical analysis of Ocean Tomo patent auctions. Research Policy, 43, 519-529. https://doi.org/10.1016/j.respol.2013.07.013 
Giummo, J. (2010). German employee inventors compensation records: A window into the returns to patented inventions. Research Policy, 39, 969-984. https://doi.org/10.1016/ j.respol.2010.04.004

Grimaldi, M., Cricelli, L., \& Rogo, F. (2018). Valuating and analyzing the patent portfolio: The patent portfolio value index. European Journal of Innovation Management, 21, 174-205. https://doi.org/10.1108/EJIM-02-2017-0009

Instituto Nacional da Propriedade Industrial (2013). Resolução No 74/2013. Retrieved from http://antigo.inpi.gov.br/legislacao-arquivo/docs/

resolucao_74-2013-deposito_dos_pedidos_de_patentes.pdf

Lee, J., \& Sohn, S. Y. (2017). What makes the first forward citation of a patent occur earlier? Scientometrics, 113, 279-298. https://doi.org/10.1007/s11192-017-2480-1

Liu, L., Cao, C., \& Song, M. (2014). China's agricultural patents: how has their value changed amid recent patent boom? Technological Forecasting and Social Change, 88, 106-121. https://doi.org/10.1016/j.techfore.2014.06.018

Martínez, C. (2010). Insight into different types of patent families. OECD Science, Technology and Industry Working Papers 2010/02. https://doi.org/10.1787/18151965

Ni, J., Shao R., Ung C.O.L., Wang, Y., \& Hu, Y. (2015). Valuation of Pharmaceutical Patents: A Comprehensive Analytical Framework Based on Technological, Commercial, and Legal Factors. Journal of Pharmaceutical Innovation, 10, 281-285. https://doi.org/10.1007/ s12247-015-9225-6

Organisation for Economic Co-operation and Development. (2009). Patent statistics manual. Paris: Organisation for Economic Co-operation and Development. Retrieved from: http://www.oecd.org/sti/inno/oecdpatentstatisticsmanual.htm

Sapsalis, E., Van Pottelsberghe de la Potterie, B., \& Navon, R. Academic versus industry patenting: An in-depth analysis of what determines patent value. Research Policy, 35, 1631-1645. https://doi.org/10.1016/j.respol.2006.09.014

Schumpeter, J. A. (1997). Teoria do desenvolvimento econômico. São Paulo: Nova Cultura.

Stevens, G. A., \& Burley, J. (1997). 3,000 Raw Ideas Equal 1 Commercial Success! Research Technology Management, 40, 16-27. https://doi.org/10.1080/08956308.1997.11671126

Xyleco. (2020). Xyleco. 2020. Retrieved from https://www.xyleco.com/

Yang, G.C., Li, G., Li, C., Zhao, Y., Zhang, J., Liu, T., Chen, D., \& Huang, M. (2015). Using the comprehensive patent citation network (CPC) to evaluate patent value. Scientometrics, 105, 1319-1346. https://doi.org/10.1007/s11192-015-1763-7

van Zeebroeck, N. (2011). The puzzle of patent value indicators. Economics of Innovation and New Technology, 20, 33-62. https://doi.org/10.1080/10438590903038256

World Intellectual Property Organization. (2014). Módulo 7: patentes. In: Propriedade Intelectual à Distância. Switzerland: Wipo/Ompi/Inpi. . Curso Geral de 